\title{
Paris saponin VII inhibits metastasis by modulating matrix metalloproteinases in colorectal cancer cells
}

\author{
LEI FAN ${ }^{1 *}$, YUHUA LI $^{1,2^{*}}$, YANG SUN $^{1 *}$, ZHENGGANG YUE $^{1}$, JIN MENG $^{3}$, XUTAO ZHANG $^{1}$, \\ RONG ZHANG $^{1}$, DIAN ZHANG ${ }^{1}$, FENG ZHANG $^{1}$ and QIBING MEI $^{1}$ \\ ${ }^{1}$ Key Laboratory of Gastrointestinal Pharmacology of Chinese Materia Medica of the State Administration of \\ Traditional Chinese Medicine, Collaborative Innovation Center for Chinese Medicine in Qinba Mountains, \\ Department of Pharmacology, School of Pharmacy, Fourth Military Medical University, \\ Xi'an, Shaanxi 710032; ${ }^{2}$ The 422nd Hospital of PLA, Zhanjiang, Guangdong 524005; \\ ${ }^{3}$ Department of Pharmacy, 309th Hospital of PLA, Beijing 100091, P.R. China
}

Received January 8, 2014; Accepted July 25, 2014

DOI: $10.3892 / \mathrm{mmr} .2014 .2728$

\begin{abstract}
Metastasis is the main cause of mortality of patients with cancer-related disease. Targeting the process of metastasis has been proposed as a potential strategy in cancer treatment. Trillium tschonoskii Maxim., a traditional Chinese medicine, is used for the treatment of numerous diseases, including cancer. The current study aimed to determine the anti-metastatic effect of Paris saponin VII (PS VII), which was extracted from T. tschonoskii Maxim., using SW620 and LoVo cells, two human metastatic colorectal cancer (CRC) cell lines. The present study conducted cell attachment, wound healing and migration assays to detect the anti-metastatic effects of PS VII on colorectal cells. In addition, gelatin zymography assay and western blot analysis were used to detect the possible mechanisms involved. The results of this study demonstrated that PS VII significantly suppresses the viability, attachment, migration and invasive abilities of CRC cells in a concentration-dependent manner. In addition, PS VII reduced the expression levels and activity of matrix metalloproteinase (MMP)-2 and MMP-9. These data indicate that PS VII reduces the metastatic capability of CRC cells, possibly via the downregulation of the expression and activity of MMP-2 and MMP-9. These results demonstrate a novel therapeutic potential for PS VII in anti-metastatic therapy.
\end{abstract}

Correspondence to: Professor Qibing Mei or Mrs. Feng Zhang, Department of Pharmacology, School of Pharmacy, Fourth Military Medical University, 169 West Changle Road, Xi'an, Shaanxi 710032, P.R. China

E-mail: qbmei53@hotmail.com

E-mail: zhangf037@163.com

*Contributed equally

Key words: Paris saponin VII, metastasis, colorectal cancer

\section{Introduction}

Colorectal cancer (CRC) is one of the most prevalent cancers worldwide (1). Although the treatment of CRC has improved, the mortality rate of CRC patients remains high. The first course of treatment for primary CRC is surgical resection and adjuvant chemotherapy; however, once metastasis occurs it is almost incurable. Previous studies have determined that $90 \%$ of mortalities due to cancer are associated with metastasis $(2,3)$. In addition, metastasis is the most common cause of mortality in patients with advanced stage CRC (4). Although irinotecan, oxaliplatin and fluorouracil-based chemotherapy regimens have improved the survival rate of patients with metastatic CRC in the last decade (5), there remains a medical requirement for more effective and well-tolerated therapies for CRC.

An increasing number of studies suggest that there are numerous natural compounds which act as cancer preventative and therapeutic agents, in addition to multiple prescription drugs that are derived from natural plant species (6-8). Trillium tschonoskii Maxim. is a perennial herb belonging to the Trilliaceae family, which is found in mid-western China (9). T. tschonoskii Maxim. has traditionally been used by the residents of China for the treatment of a number of conditions, including hypertension, headache, neurasthenia, giddiness, cancer and for ameliorating pain. Previous studies have demonstrated that numerous bioactive compounds, including steroidal saponins and steroidal glycosides, are found in a number of species in the Trillium genus, including Trillium erectum $(10,11)$, Trillium kamtschaticum (12) and T. tschonoskii. A previous study extracted a steroidal saponin, Paris saponin VII (PS VII), from T. tschonoskii and evaluated its growth-inhibitory effect on HT-29 and SW-620 cells in a murine xenograft tumor model. In addition, the protective effects of PS VII against AOM/DSS-induced colitis-associated carcinogenesis were investigated in ICR mice.

In the present study, the anti-metastatic activities of PS VII were investigated in two metastatic CRC cell lines. The present study aimed to explore the molecular mechanisms for 
the effects of PS VII on metastatic colorectal cancer, in the hope to provide a basis for the future development of PS VII as a novel anti-colorectal cancer agent, for both primary and metastatic diseases.

\section{Materials and methods}

Materials and chemicals. PS VII, with a purity of $>99 \%$, was isolated from the root and rhizome of $T$. tschonoskii Maxim. which was obtained from the Qinba Mountains (Ankang, China) (13). The chemical structure of PS VII is shown in Fig. 1. PS VII was dissolved in dimethylsulfoxide (DMSO) at $1 \mathrm{M}$ and stocked at $-20^{\circ} \mathrm{C}$ in aliquots. Trypan blue, Triton X-100, pyruvate, penicillin $\mathrm{G}$ and streptomycin were obtained from Sigma (St. Louis, MO, USA). RPMI-1640 and fetal bovine serum (FBS) were purchased from Corning Inc. (Corning, NY, USA). Rabbit polyclonal anti-MMP-2 and MMP-9 antibodies were purchased from Santa Cruz Biotechnology, Inc. (Santa Cruz, CA, USA). Matrigel was purchased from BD Biosciences (Franklin Lakes, NJ, USA). Materials and chemicals for electrophoresis were obtained from Bio-Rad Laboratories (Hercules, CA, USA). All other chemicals were of analytical reagent grade and purchased from Sinopharm Chemical Reagent Co., Ltd (Shanghai, China).

Cell line and culture conditions. SW620 and LoVo human colon carcinoma cell lines [American Type Culture Collection (ATCC), Rockville, MD, USA] were cultured in RPMI-1640 medium, and human umbilical vein endothelial cells (HUVECs; which were supplied by Prof. Zhou Siyuan, Department of Pharmacology) were cultured in Dulbecco's modified Eagle's medium. For cell maintenance, the basal medium was supplemented with $10 \% \mathrm{FBS}, 100 \mathrm{U} / \mathrm{ml}$ penicillin and $100 \mathrm{U} / \mathrm{ml}$ streptomycin. The solvent control contained an equivalent amount of DMSO corresponding to the highest concentration of PS VII that was used.

Cell viability assay. The effects of PS VII on cell viability were determined using an MTT assay. Cells were seeded in a 96-well plate at a density 5,000 cells per well and incubated with or without PS VII for $24 \mathrm{~h}$ at $37^{\circ} \mathrm{C}$. After incubation, $20 \mu \mathrm{l}$ MTT solution $(5 \mathrm{mg} / \mathrm{ml})$ was added to each well and the plate was incubated for a further $4 \mathrm{~h}$ at $37^{\circ} \mathrm{C}$. The supernatants were aspirated carefully and $200 \mu \mathrm{l}$ DMSO was added, and then the plate was subjected to vibration for $20 \mathrm{sec}$. The optical density (OD) of the cell suspension was measured at a wavelength of $490 \mathrm{~nm}$ using a microplate reader (iMark model 680; Bio-Rad Laboratories). The inhibition rate was calculated using the following formula: Inhibition $=\left(1-\mathrm{OD}_{\text {treatment group }} / \mathrm{OD}_{\text {control group }}\right) \times 100$. All experiments were performed in triplicate.

Cell-matrix and cell-cell attachment assays. Cells contained in dishes were pretreated with or without PS VII $(0.3$ and $1 \mu \mathrm{M})$ for $24 \mathrm{~h}$. Following pretreatment, the cells were detached from the dishes via incubation with $15 \mathrm{mM}$ EDTA, washed twice with phosphate-buffered saline (PBS) and once with serum-free medium (SFM), counted and seeded into 96-well plates at a density of 5,000 cells per well. For cell-matrix attachment assays (13), the 96-well plates (Costar, Corning Inc., Corning, NY, USA) were precoated with Matrigel (BD

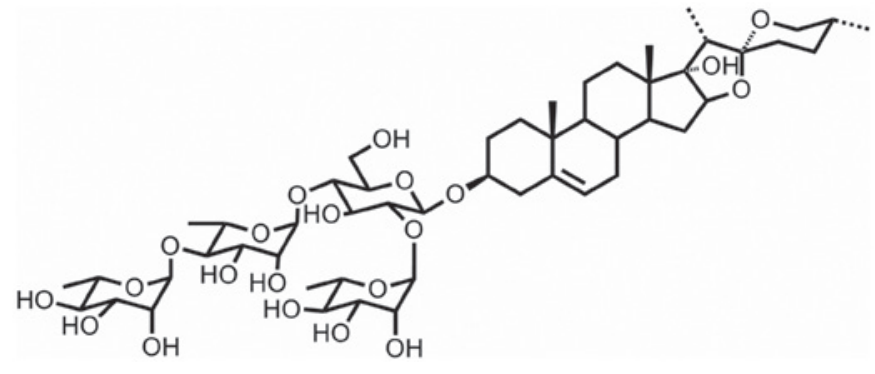

Figure 1. Chemical structure of Paris saponin VII

Biosciences, Franklin Lakes, NJ, USA) or bovine serum albumin as a background control, incubated for $1 \mathrm{~h}$ at room temperature (RT) and $1 \mathrm{~h}$ at $37^{\circ} \mathrm{C}$, and washed with PBS, prior to the assay. Plates with CRC cells were incubated for $1 \mathrm{~h}$ at $37^{\circ} \mathrm{C}$, cells were washed twice with PBS and attached cells were assessed using the MTT method. For cell-cell attachment assays (14) HUVECs were plated in growth medium at a density of 30,000 cells per well and incubated at $37^{\circ} \mathrm{C}$ in $5 \% \mathrm{CO}_{2}$ for $24 \mathrm{~h}$ prior to the assay. The plates containing the $\mathrm{CRC}$ cells were incubated in a humidified atmosphere for $1 \mathrm{~h}$, washed four times with warm SFM, stained with a $0.25 \%$ rose bengal-PBS solution and incubated for $5 \mathrm{~min}$ at RT. Subsequently, cells were washed twice with SFM. Rose bengal was dissolved in a 95\% ethanol-PBS solution (1:1) and detected using a microplate reader. Duplicate wells containing only HUVECs were included in each experiment as background controls. After subtracting the OD value of background wells, the rate of attachment was determined as the ratio of attaching cells to that of the non-washed group.

Wound-healing assay. Cells were seeded in 6-well plates at a density of $5 \times 10^{5}$ cells per well. Once the cells reached $90 \%$ confluence, a wound area was carefully created by scraping the cell monolayer with a sterile $200-\mu 1$ pipette tip, from one end of the well to the other. The detached cells were removed by washing with PBS. Subsequently, the cells were incubated at different concentrations of PS VII $(0.3$ and $1 \mu \mathrm{M})$. Migration of cells into the wounded region was observed using an Olympus CK-2 inverted microscope (Olympus, Tokyo, Japan) and images were captured at 0 and $24 \mathrm{~h}$ at $\times 100$ magnification. The wound area was measured using the image processing program ImageJ (NIH, Bethesda, Maryland, USA). The cell wound closure rate was calculated using the following equation: Wound closure $=\left[1-\left(\right.\right.$ wound area at $T_{t} /$ wound area at $\left.T_{0}\right) \times 100$, where $T_{t}$ is the time passed since wounding and $\mathrm{T}_{0}$ is the time the wound was created. The experiments were performed in triplicate.

Cell invasion determinations. Cell invasion was determined using Matrigel-coated Transwell cell culture chambers ( $8 \mu \mathrm{m}$ pore size) (Millipore, Billerica, MA, USA) as described previously $(15,16)$. Cells were maintained for $24 \mathrm{~h}$ in SFM, trypsinized and resuspended in serum-free RPMI-1640 medium. Following resuspension, cells were placed in the upper chamber of the Transwell insert ( $5 \times 10^{4}$ cells per well) and incubated with different concentrations of PS VII $(0.3$ or $1 \mu \mathrm{M})$. RPMI-1640 medium containing $10 \%$ FBS was added to the lower chamber. The cells were incubated at $37^{\circ} \mathrm{C}$ in an incubator supplemented 


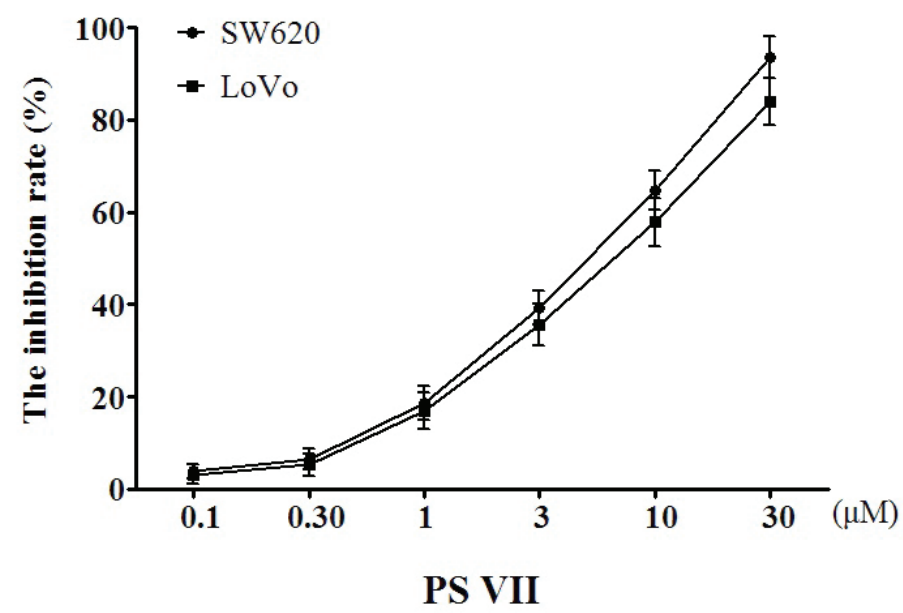

Figure 2. Effects of Paris saponin VII (PS VII) on SW620 and LoVo cell viability. Cells were incubated with or without PS VII $(0.1,0.3,1,3,10$ or $30 \mu$ M) for $24 \mathrm{~h}$ at $37^{\circ} \mathrm{C}$. Following incubation, the effects of PS VII on cell viability were determined using an MTT assay. The inhibition rate was calculated using the optical density $(\mathrm{OD})$ values and the following formula: Inhibition rate $=\left(1-\mathrm{OD}_{\text {treatment group }} / \mathrm{OD}_{\text {control group }}\right) \mathrm{x} 100$. All experiments were performed in triplicate. All data are represented as the mean \pm standard deviation of five independent experiments.

with $5 \% \mathrm{CO}_{2}$ for $24 \mathrm{~h}$; non-invasive cells in the upper chamber were removed by wiping with a cotton swab and invasive cells were fixed with $4 \%$ formaldehyde in PBS and stained with $1 \%$ crystal violet in $2 \%$ ethanol. Images of cells on the lower surface of the filter were captured under a light microscope (TS100; Nikon Corporation, Tokyo, Japan; x100 magnification). The inserts were washed with $33 \%$ acetic acid. The absorbance of the washing buffer at $570 \mathrm{~nm}$ was determined for each well using a microplate reader. Cell-free inserts which only contained medium were included in duplicate throughout each experiment as OD background controls. The reported OD data represent the mean background-corrected values \pm standard deviation (SD) obtained from three independent experiments in duplicate.

Gelatin zymography. The zymographic analysis was adapted from Surgucheva et al (17). Cells were seeded in a 24 -well plate at a density of $5 \times 10^{5}$ cells per well and incubated with PS VII $(0.3$ or $1 \mu \mathrm{M})$ for $24 \mathrm{~h}$ at $37^{\circ} \mathrm{C}$. Following incubation, conditional medium was harvested and then electrophoresed on $15 \%$ denaturing sodium dodecyl sulphate (SDS) polyacrylamide gels containing $1 \mathrm{mg} / \mathrm{ml}$ gelatin (Sangon, Shanghai, China). Gels were washed twice in rinsing buffer $(50 \mathrm{mM}$ Tris-HCl, $5 \mathrm{mM} \mathrm{CaCl}_{2}, 2.5 \%$ Triton-X 100, $1 \mu \mathrm{M} \mathrm{ZnCl}_{2}$ and $0.05 \% \mathrm{NaN}_{3}$ ) for $1 \mathrm{~h}$ and then incubated for $24 \mathrm{~h}$ at $37^{\circ} \mathrm{C}$ in the rinsing buffer without Triton-X 100, so that renaturation of the enzyme could occur. Gels were stained with Coomassie blue R-250 (Bio-Rad Laboratories) and destained with 5\% acetic acid containing $10 \%$ methanol. Gelatinolytic activities were visualized as clear bands against a blue background.

Western blotting. Following treatment with PS VII (0.3 and $1 \mu \mathrm{M}$ ) for 24 and $48 \mathrm{~h}$, cells were washed twice with PBS and treated with extraction buffer (50 mM Tris-Cl, pH 7.5, $150 \mathrm{mM}$ $\mathrm{NaCl}, 0.1 \%$ SDS, $1 \%$ NP-40, and $0.5 \%$ deoxycholic acid). The cell extractions were collected, centrifuged at $10,000 \mathrm{x} \mathrm{g}$ for $15 \mathrm{~min}$ at $4^{\circ} \mathrm{C}$ and the cell lysates collected as supernatants. The cell lysates were subjected to SDS-PAGE and transferred to nitrocellulose membranes (Millipore, Bedford, MA, USA).
The membranes were blocked with $5 \%(\mathrm{w} / \mathrm{v})$ non-fat milk in PBS containing $0.1 \%$ Tween-20, and then blotted with primary antibody. Subsequently, the membranes were incubated with an appropriate secondary antibody (horseradish peroxidase-conjugated goat anti-mouse or anti-rabbit IgG). The immuno-detected proteins were then revealed using enhanced chemiluminescence (ChemiScope5000; Clinx Science Instruments, CO., Ltd., Shanghai, China).

Statistics. Results are expressed as the mean \pm SD. Two group comparisons were evaluated using Student's t-test. $\mathrm{P}<0.05$ was considered to indicate a statistically significant difference.

\section{Results}

PS VII inhibits the viability of CRC cells. The viability of SW620 and LoVo cells treated with PS VII at different concentrations $(0.1,0.3,1,3,10$ or $30 \mu \mathrm{M})$ for $24 \mathrm{~h}$ was determined using an MTT reduction assay. As shown in Fig. 2, PS VII reduced the cell viability rate in a concentration-dependent manner. Higher concentrations of PS VII inhibited the growth of CRC cells directly. Hence, in order to observe the effect of PS VII on the attachment, migration and invasion of CRC cells more accurately and clearly, concentrations for the following experiments were selected which demonstrated no obvious cytotoxicity to the proliferation of the cells $(0.3$ and $1 \mu \mathrm{M})$.

PS VII inhibits cell attachment. To determine whether PS VII affects the attachment ability of CRC cells, the attachment of the cells to Matrigel and vascular endothelial cells was assessed. Matrigel is an extracellular matrix (ECM) which is composed of laminin, collagen type IV, nidogen and heparan sulfate glycoprotein. As shown in Fig. 3A, pretreatment with 0.3 and $1 \mu \mathrm{M}$ PS VII for $24 \mathrm{~h}$ reduced the attachment of SW620 and LoVo cells to Matrigel following incubation for $1 \mathrm{~h}$, compared with that of the control cells. The potential effect of PS VII on the attachment of CRC cells to vascular endothelial cells was investigated via incubation with HUVECs. As shown 

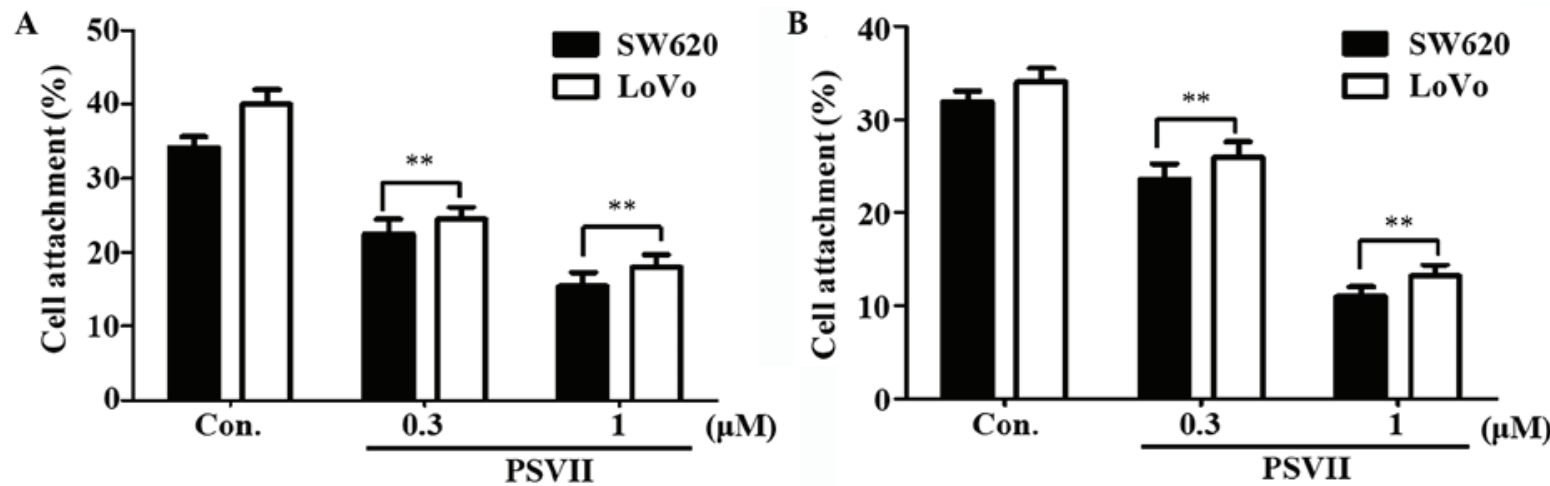

Figure 3. Effects of Paris saponin VII (PS VII) on cell attachment. Cells pretreated with or without different concentrations of PS VII $(0.3$ and $1 \mu \mathrm{M})$ were added to plates pre-coated with Matrigel or human umbilical vein endothelial cells (HUVECs) and cells were incubated for $1 \mathrm{~h}$ at $37^{\circ} \mathrm{C}$, then washed and quantified. The effect of PS VII pretreatment on cell attachment to (A) Matrigel and (B) HUVECs. The experiments were performed in triplicate, ${ }^{* *} \mathrm{P}<0.01$ vs. the control (Student's two-tailed t-test).
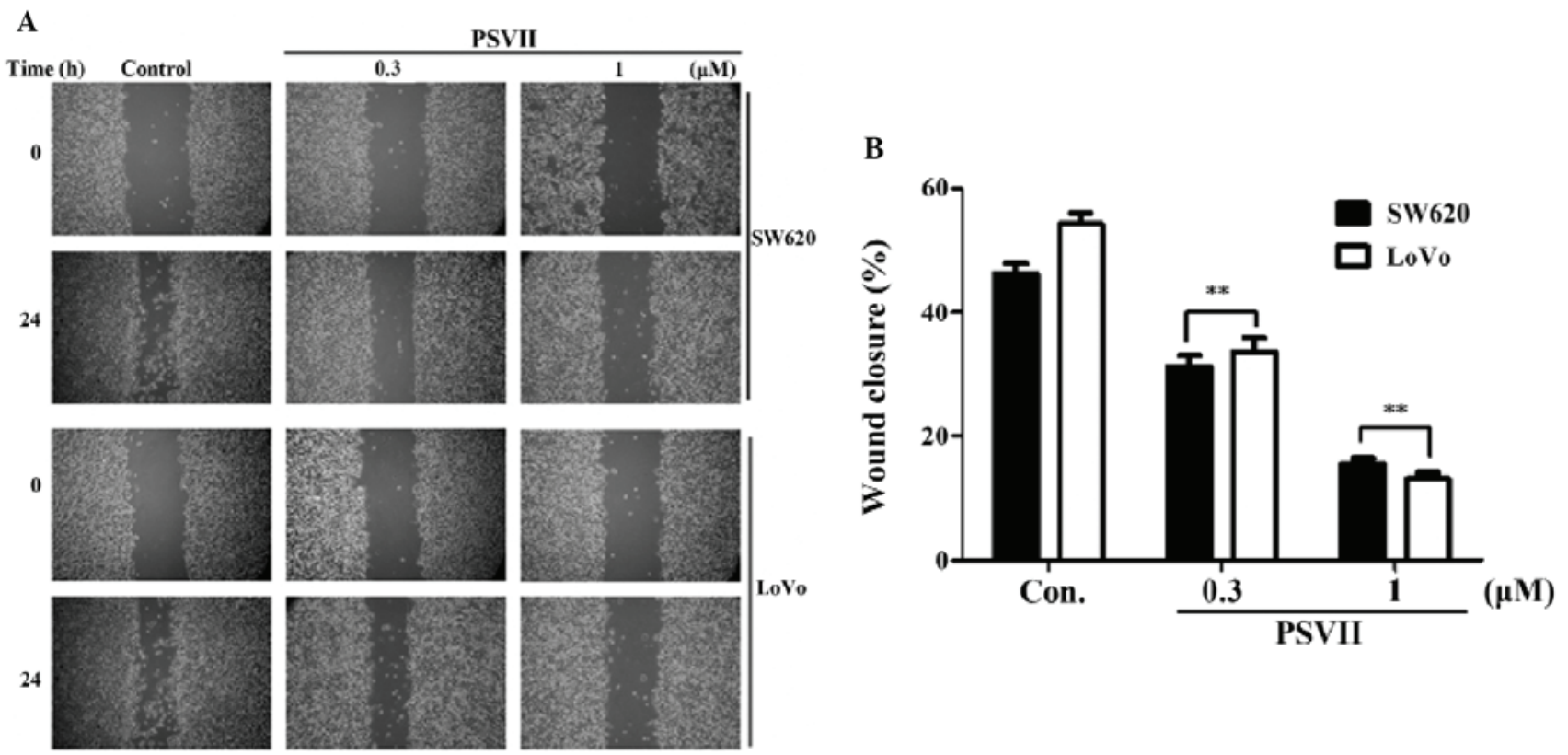

Figure 4. Effects of Paris saponin VII (PS VII) on cell migration. (A) Migration of SW620 and LoVo cancer cell lines was assayed by wound-healing assay. Cells were cultured to an almost confluent cell monolayer, a scratch-wound was created on the cell surface using a micropipette tip, and then PS VII (0.3 and $1 \mu \mathrm{M}$ ) was added. The cultures were incubated at $37^{\circ} \mathrm{C}$ and images were captured with a microscope at 0 and $24 \mathrm{~h}$ (magnification, $\mathrm{x} 100$ ). (B) The cell wound closure rate was measured at $24 \mathrm{~h}$ and was calculated according to the equation: Wound closure $=\left[1-\left(\right.\right.$ wound area at $T_{t} /$ wound area at $\left.T_{0}\right) \times 100$, where $T_{t}$ is the time passed since wounding and $\mathrm{T}_{0}$ is the time the wound was created. The experiments were performed in triplicate, ${ }^{* *} \mathrm{P}<0.01 \mathrm{vs}$. the control (Student's two-tailed t-test).

in Fig. 3B, SW620 and LoVo cells that were pretreated with 0.3 and $1 \mu \mathrm{M}$ PS VII for $24 \mathrm{~h}$ demonstrated an impaired ability to attach to HUVECs after incubation for $1 \mathrm{~h}$, compared with that of the control cells.

PS VII inhibits the migration of SW620 and LoVo cells in vitro. One characteristic of tumor metastasis is the increased migratory ability of tumor cells. The inhibition of migration of SW620 and LoVo cells by PS VII was investigated using wound-healing assays. Cells were incubated with different concentrations of PS VII for $24 \mathrm{~h}$. Higher concentrations of PS VII $(1 \mu \mathrm{M})$ were observed to significantly increase the inhibition of cell migration in the two cell lines compared with that of the control cells (Fig. 4).
PS VII inhibits the invasion of SW620 and LoVo cells in vitro. In order to determine the inhibitory effect of PS VII on the invasion of SW620 and LoVo cells across the ECM, the cells that invaded through the Matrigel-coated polycarbonate filter in the Transwell chamber were analyzed. The results are presented in Fig. 5. The majority of SW620 and LoVo cells invaded from the upper to the lower chamber in the control group; however, the presence of PS VII inhibited the penetration of the Matrigel-coated filter by SW620 and LoVo cells (Fig. 5A). This inhibitory effect was greatest at a concentration of $1 \mu \mathrm{M}$. The quantification of cells in the lower chamber from Fig. 5B indicated that PS VII significantly inhibited SW620 and LoVo cell invasion and that this inhibitory effect was concentration-dependent. 
A

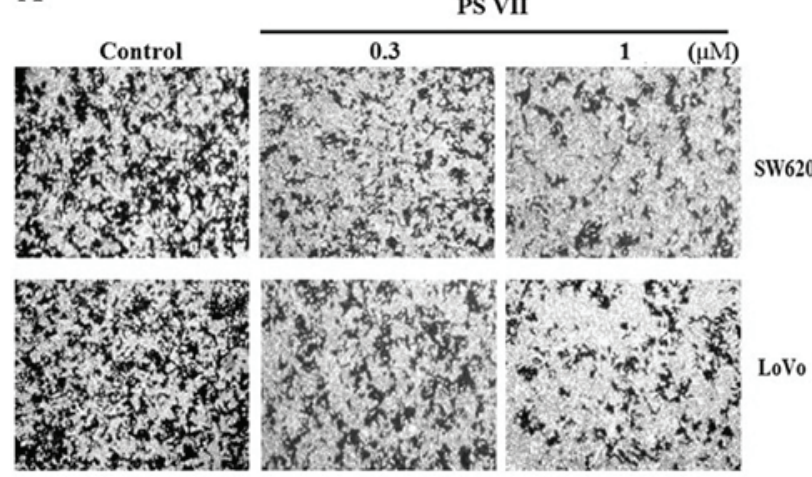

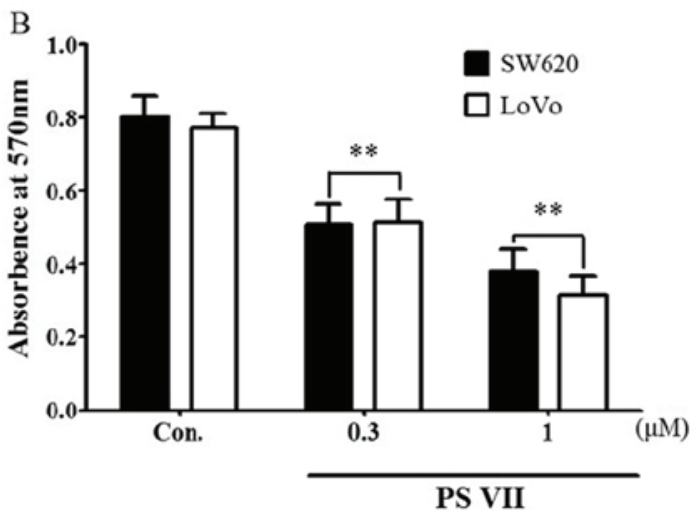

Figure 5. Effect of Paris saponin VII (PS VII) on the invasiveness of SW620 and LoVo cells. (A) Cells were treated with PS VII (0.3 and $1 \mu \mathrm{M})$ for $24 \mathrm{~h}$ and a cell invasion assay was performed. Images of the invaded cells were captured with a microscope (magnification, x100). (B) The invaded cells were quantified via the absorbance of crystal violet in the 33\% acetic acid used to wash the cells that invaded the underside of the porous polycarbonate membrane. The experiments were performed in triplicate, and are represented as the mean of the three experiments \pm standard deviation. ${ }^{* * *} \mathrm{P}<0.01$ vs. the control.

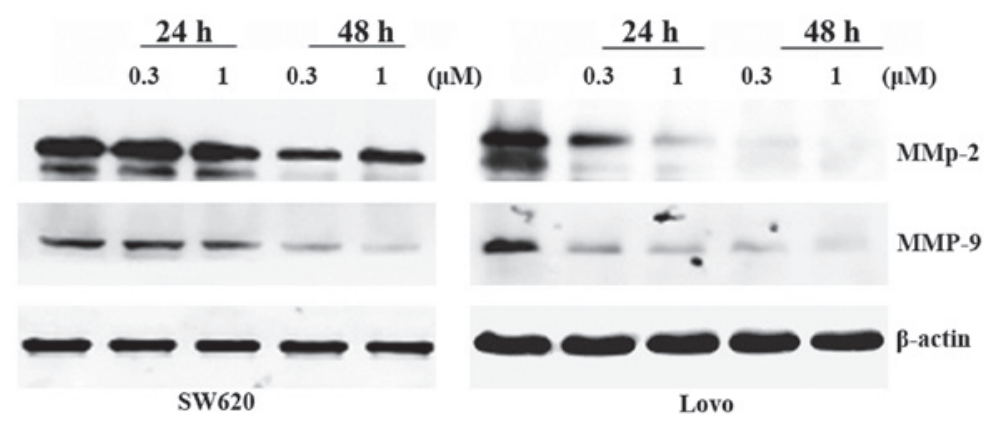

Figure 6. Effect of Paris saponin VII (PS VII) on the expression of matrix metalloproteinase (MMP)-2 and MMP-9. Cells were treated with PS VII for 24 and $48 \mathrm{~h}$, and the protein expression levels were estimated using western blot analysis.
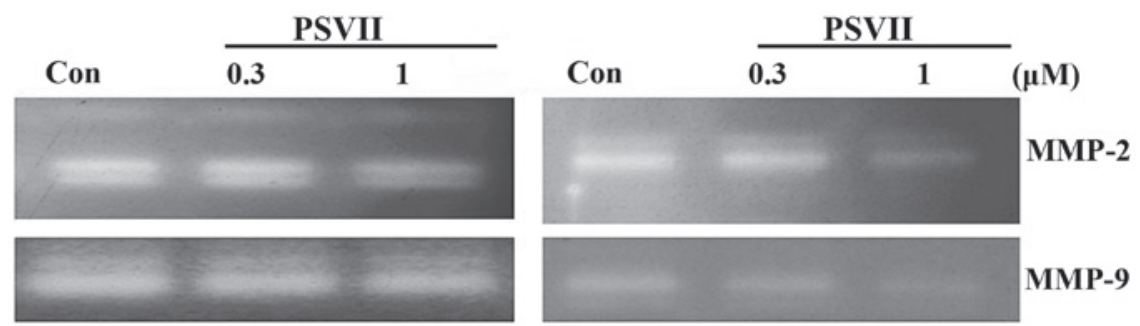

Figure 7. Effect of Paris saponin VII (PS VII) on the activation of matrix metalloproteinase (MMP)-2 and MMP-9 in SW620 and LoVo cells. Cells were incubated for $24 \mathrm{~h}$ with a vehicle control or PS VII $(0.3$ and $1 \mu \mathrm{M})$. Conditioning media were used for the measurement of MMP-2 and MMP-9 protein levels by gelatin zymography.

PS VII affects the expression levels of metastasis-related proteins in SW620 and LoVo cells. The expression of MMPs is crucial to ECM degradation, which is required for cell invasion. Hence, the effect of PS VII on the expression of MMPs was investigated by western blot analysis. The results demonstrated that PS VII suppresses the expression levels of MMP-2 and MMP-9 proteins in a concentration-dependent manner (Fig. 6). These effects may lead to the inhibition of the invasive ability of SW620 and LoVo cells following exposure to PS VII.

PS VII suppresses the activity of MMP-2 and MMP-9. Although the protein expression of MMP-2 and MMP-9 was downregulated by PS VII, the activity of these two enzymes during treatment with PS VII required further investigation. Gelatinolytic activity at molecular masses of 72 and $92 \mathrm{kDa}$ (which correspond to the molecular mass of MMP-2 and MMP-9, respectively) was detected in the conditioned medium of cells treated with PS VII. The activity of MMP-2 and MMP-9 in the two cell lines was markedly repressed by PS VII in a concentration-dependent manner (Fig. 7).

\section{Discussion}

Saponins are natural glycosides which possess a wide range of pharmacological properties, including cytotoxic activity. In a previous study, it was determined that PS VII, a saponin compound isolated from T. tschonoskii Maxim., possesses a 
growth-inhibitory effect in vitro and in vivo. Furthermore, non-apoptotic processes have also been revealed to be involved in saponin cytotoxic activity, including cell cycle arrest (18), autophagic cell death stimulation (19), inhibition of metastasis (20) and cytoskeleton disintegration (21).

The suppression of cancer metastasis is an urgent therapeutic requirement in the treatment of CRC. As resection of the primary tumors is the treatment of choice, $30 \%$ of patients with stage III CRC develop local recurrence or distant metastasis within 5 years of curative resection (22). However, the majority of existing therapies only inhibit cancer cell proliferation and little has been accomplished in terms of treating cancer metastasis. Cancer cells are released from their primary locations early in carcinogenesis, hence anti-metastasis drugs would be most effective if they could assist in preventing the spread of cancer cells in addition to suppressing existing tumor colonies. It has previously been demonstrated that PS VII exerts a growth-inhibitory effect on CRC cells. In the present study, the anti-metastatic activity of PS VII was observed in two metastatic CRC cell lines, SW620 and LoVo.

Metastasis is a complex, multistep process that consists of a cascade of interrelated sequential steps, including migration, invasion, adhesion, infiltration, colonization at a distant site and the subsequent formation of new microvessels (23). To successfully metastasize, cancer cells must acquire the ability to migrate. The migration of cells is based on cycles of lamellipodial extension, attachment, cell body translocation, and retraction of the cell (24). In a non-cytotoxic dose, the present study evaluated the anti-migratory activity of PS VII via a wound-healing assay which is a classic in vitro assay of cell migration. The results revealed that PS VII reduces cell migration in a concentration-dependent manner.

In the present study, the invasive ability of cells was evaluated via a Transwell invasion assay. It was demonstrated that PS VII inhibits the invasion rate of cells in a concentration-dependent manner. Cell invasion requires proteolysis of ECM components and transmigration to penetrate it. In these steps, the expression of proteolytic enzymes, such as MMPs, is crucial for ECM degradation (25). Two members of the MMP family, the 72-kDa type IV collagenase MMP-2 (gelatinase A) and the $92-\mathrm{kD}$ type IV collagenase MMP-9 (gelatinase B), have been shown to be highly expressed and to be important mediators in the pathogenesis of CRC metastasis (26). Increased MMP-2 and MMP-9 protein expression levels are associated with a poor prognosis in patients with CRC (27). Therefore, the present study investigated whether the inhibitory effect of PS VII on cell invasion occurred via the suppression of MMP-2 and MMP-9 expression. The results of gelatin zymography and western blot assays verified that PS VII suppressed the activation and expression of MMP-2 and MMP-9.

In the process of metastasis, the first step of migration involves attachment of cells to the ECM and the process of invading and exiting blood vessels requires attachment of cells to the vascular endothelium. Therefore, the ability of cells adhere to the ECM and vascular endothelial cells was assessed in this study. Matrigel was used as an ECM in the migration and invasion assays. The results demonstrated that cells which were pretreated with PS VII exhibited reduced cell attachment to Matrigel. In the cell-cell attachment assays, PS VII pretreatment reduced the ability of cells to adhere to vascular endothelial cells. These results indicate that PS VII also inhibits metastasis by impairing the ability of cells to adhere.

In conclusion, the results of the current study indicate that PS VII obtained from T. tschonoskii Maxim. inhibits the migration, invasion and adhesion of human metastatic CRC cells through inhibition of the activity and expression of MMP-2 and MMP-9. Hence, PS VII may be a promising agent for therapeutic and preventive purposes in the treatment of CRC, by not only suppressing the proliferation of cancer cells but also by inhibiting metastasis-associated events.

\section{Acknowledgements}

The authors of the present study would like to thank the Department of Forestry of Shaanxi Province and the Taibaishan Natural Preserve of Shaanxi Province for helping us collect the Trillium tschonoskii Maxim. The present study was supported by grants from the Taibaishan Natural Preserve of Shaanxi Province, the National Nature Science Foundation of China (no. 81302787), and the Postdoctoral Science Foundation of China (nos. 2012M512102 and 2013T60964).

\section{References}

1. Siegel R, Naishadham D and Jemal A: Cancer statistics, 2012. CA Cancer J Clin 62: 10-29, 2012.

2. Gupta GP and Massagué J: Cancer metastasis: building a framework. Cell 127: 679-695, 2006.

3. Steeg PS: Tumor metastasis: mechanistic insights and clinical challenges. Nat Med 12: 895-904, 2006.

4. Sanoff HK, Sargent DJ, Campbell ME, et al: Five-year data and prognostic factor analysis of oxaliplatin and irinotecan combinations for advanced colorectal cancer: N9741. J Clin Oncol 26: 5721-5727, 2008

5. Prat A, Casado E and Cortés J: New approaches in angiogenic targeting for colorectal cancer. World J Gastroenterol 13: 5857-5866, 2007.

6. Sarkar FH, Li Y, Wang Z and Kong D: Cellular signaling perturbation by natural products. Cell Signal 21: 1541-1547, 2009.

7. Cragg GM and Newman DJ: Natural products: a continuing source of novel drug leads. Biochim Biophys Acta 1830: 3670-3695, 2013.

8. Reddy L, Odhav B and Bhoola KD: Natural products for cancer prevention: a global perspective. Pharmacol Ther 99: 1-13, 2003.

9. Li Q, Xiao M, Guo L, et al: Genetic diversity and genetic structure of an endangered species, Trillium tschonoskii. Biochem Genet 43: 445-458, 2005.

10. Yokosuka A and Mimaki Y: Steroidal glycosides from the underground parts of Trillium erectum and their cytotoxic activity. Phytochemistry 69: 2724-2730, 2008.

11. Hayes PY, Lehmann R, Penman K, Kitching W and De Voss JJ: Steroidal saponins from the roots of Trillium erectum (Beth root). Phy tochemistry 70: 105-113, 2009.

12. Ono M, Sugita F, Shigematsu S, et al: Three new steroid glycosides from the underground parts of Trillium kamtschaticum. Chem Pharm Bull (Tokyo) 55: 1093-1096, 2007.

13. Smicun Y, Gil O, Devine K and Fishman DA: S1P and LPA have an attachment-dependent regulatory effect on invasion of epithelial ovarian cancer cells. Gynecol Oncol 107: 298-309, 2007.

14. Gamble JR and Vadas MA: A new assay for the measurement of the attachment of neutrophils and other cell types to endothelial cells. J Immunol Methods 109: 175-184, 1988.

15. Hsu SC, Kuo CL, Lin JP, et al: Crude extracts of Euchresta formosana radix inhibit invasion and migration of human hepatocellular carcinoma cells. Anticancer Res 27: 2377-2384, 2007.

16. Huang YT, Hwang JJ, Lee LT, et al: Inhibitory effects of a luteinizing hormone-releasing hormone agonist on basal and epidermal growth factor-induced cell proliferation and metastasis-associated properties in human epidermoid carcinoma A431 cells. Int J Cancer 99: 505-513, 2002. 
17. Surgucheva IG, Sivak JM, Fini ME, Palazzo RE and Surguchov AP: Effect of gamma-synuclein overexpression on matrix metalloproteinases in retinoblastoma Y79 cells. Arch Biochem Biophys 410: 167-176, 2003.

18. Qin H, Du X, Zhang Y and Wang R: Platycodin D, a triterpenoid saponin from Platycodon grandiflorum, induces G2/M arrest and apoptosis in human hepatoma HepG2 cells by modulating the PI3K/Akt pathway. Tumour Biol 35: 1267-1274, 2014

19. Xu MY,Lee DH, Joo EJ, Son KH and Kim YS: Akebia saponin PA induces autophagic and apoptotic cell death in AGS human gastric cancer cells. Food Chem Toxicol 59: 703-708, 2013.

20. Yoon JH, Choi YJ and Lee SG: Ginsenoside Rh1 suppresses matrix metalloproteinase-1 expression through inhibition of activator protein-1 and mitogen-activated protein kinase signaling pathway in human hepatocellular carcinoma cells. Eur J Pharmacol 679: 24-33, 2012.

21. Ha TS, Lee JS, Choi JY and Park HY: Ginseng total saponin modulates podocyte p130Cas in diabetic condition. J Ginseng Res 37: 94-99, 2013.
22. Kobayashi H, Mochizuki H, Sugihara K, et al: Characteristics of recurrence and surveillance tools after curative resection for colorectal cancer: a multicenter study. Surgery 141: 67-75, 2007.

23. Weng CJ and Yen GC: Chemopreventive effects of dietary phytochemicals against cancer invasion and metastasis: phenolic acids, monophenol, polyphenol, and their derivatives. Cancer Treat Rev 38: 76-87, 2012.

24. Berrier AL and Yamada KM: Cell-matrix adhesion. J Cell Physiol 213: 565-573, 2007.

25. Friedl P and Wolf K: Tumour-cell invasion and migration: diversity and escape mechanisms. Nat Rev Cancer 3: 362-374, 2003.

26. Liska V, Sutnar A, Jr LH, et al: Matrix metalloproteinases and their inhibitors in correlation to proliferative and classical tumour markers during surgical therapy of colorectal liver metastases. Bratisl Lek Listy 113: 108-113, 2012.

27. Langers AM, Verspaget HW, Hawinkels LJ, et al: MMP-2 and MMP-9 in normal mucosa are independently associated with outcome of colorectal cancer patients. Br J Cancer 106 1495-1498, 2012. 